\title{
CARACTERÍSTICAS AGRONÔMICAS E QUALIDADE FISIOLÓGICA DE SEMENTES DE SOJA EM FUNÇÃO DA ADUBAÇÃO FOLIAR COM BORO E ZINCO
}

\author{
Allan Hisashi Nakao ${ }^{1 *}$, Nídia Raquel Costa ${ }^{2}$, Marcelo Andreotti ${ }^{3}$, Marcelo Fernando Pereira \\ Souza $^{4}$, Lourdes Dickmann ${ }^{5}$, Daniela Capelas Centeno ${ }^{5}$, Gabriela Chrisyal Catalani ${ }^{5}$ \\ ${ }^{1}$ Professor Dr., Centro Universitário de Santa Fé do Sul - SP, Brasil. *E-mail do autor correspondente: \\ allanhisashinakao@gmail.com \\ 2 Pós doutoranda, Programa de Pós-graduação em Agronomia, Universidade Estadual Paulista (UNESP), \\ Faculdade de Ciências Agronômicas, Câmpus de Botucatu - SP, Brasil. \\ ${ }^{3}$ Professor Dr., Universidade Estadual Paulista (UNESP), Faculdade de Engenharia, Câmpus de Ilha Solteira - \\ SP, Brasil. \\ ${ }^{4}$ Professor Dr., Escola Técnica de Educação Profissional e Tecnologia de Alta Floresta, Alta Floresta - MT, \\ Brasil. \\ 5 Doutoranda, Programa de Pós-graduação em Agronomia, Universidade Estadual Paulista (UNESP), \\ Faculdade de Engenharia, Câmpus de Ilha Solteira - SP.
}

Recebido: 19/09/2017; Aceito: 22/06/2018

RESUMO: Diversos fatores podem influenciar o desenvolvimento e a produção da cultura da soja, podendo-se destacar principalmente a deficiência nutricional e a qualidade fisiológica das sementes. Desta forma, a presente pesquisa objetivou avaliar os teores foliares nutricionais, os componentes da produção e a produtividade de sementes de soja, além da qualidade fisiológica das sementes em função da adubação foliar com Boro (B) e Zinco (Zn). O delineamento experimental foi o de blocos casualizados, com 10 tratamentos e 4 repetições. Os tratamentos foram constituídos pela aplicação foliar, de diferentes dosagens de $\mathrm{B}$ e Zn combinadas ou não na cultura da soja. Constatou-se que as diferentes combinações e dosagens de B e Zn, aplicados via foliar na cultura da soja não melhoraram os teores foliares nutricionais, os componentes da produção e produtividade de sementes da soja, assim como a qualidade fisiológica das sementes.

Palavras-chave: Glycine max. Micronutrientes. Teores nutricionais foliares. Produtividade de grãos. Potencial fisiológico.

\section{AGRONOMIC CHARACTERISTICS AND PHYSIOLOGICAL QUALITY OF SOYBEAN IN FERTILIZER FUNCTION LEAF WITH BORON AND ZINC}

\begin{abstract}
Several factors may influence the development and soybean production, especially being able to high light the nutritional deficiency and physiological seed quality. Thus, the present study aimed to evaluate the foliar nutritional quality, the components of production and yield of soybean seeds, in addition to the physiological quality of seeds depending on foliar fertilization with boron (B) and zinc (Zn). The experimental design was a randomized block with 10 treatments and 4 repetitions. The treatments were constituted by
\end{abstract}


the foliar application of different rates of B and $\mathrm{Zn}$, combined or not in soybean crop. It was found that different combinations and rates of $\mathrm{B}$ and $\mathrm{Zn}$ applied to the leaves of soybean did not improve the foliar nutrition, the components of production and yield of soybean seeds, as well as physiological seed quality.

Key words: Glycine max. Micronutrients. Foliar nutritional contente. Grain yield. Physiological potential.

\section{INTRODUÇÃO}

A cultura da soja é a mais importante oleaginosa em produção sob cultivo extensivo no Brasil (LANA et al., 2007). O grão da soja constitui-se numa excelente fonte de proteína e óleo vegetal, atendendo satisfatoriamente as exigências alimentares humanas e animais. Atualmente, do ponto de vista alimentar e econômico, é a mais importante oleaginosa cultivada no mundo (EMBRAPA, 2006).

Na maioria dos sistemas produtivos, a cultura tem garantido posição de destaque, com produtividade média de grãos em torno de $3.000 \mathrm{~kg} \mathrm{ha}^{-1}$ (CONAB, 2015). Diversos fatores podem influenciar o satisfatório desenvolvimento e produção da cultura da soja, como os estresses bióticos e abióticos, podendo-se destacar principalmente a deficiência nutricional e a qualidade fisiológica das sementes. Desta forma, o correto manejo da cultura com relação a estes aspectos são de extrema relevância com vistas ao maior rendimento.

A importância dos avanços tecnológicos no conhecimento das exigências nutricionais da soja nos diversos sistemas produtivos, proporcionam um manejo eficiente da cultura e aumento em produtividade. Diversas pesquisas enfatizam a importância do correto manejo da adubação na cultura da soja, tanto com relação à aplicação de macronutrientes quanto de micronutrientes, obtendo resultados satisfatórios em produtividade de grãos da cultura (BEVILAQUA et al., 2002; CERETTA et al., 2005; KAPPES et al., 2008; SOUZA et al., 2008; GONÇALVES JÚNIOR et al., 2010; HARTER e BARROS, 2011).

Os micronutrientes, em diversas situações de cultivo, podem torna-se limitantes para a obtenção de produtividades adequadas, sendo este problema mais acentuado com o cultivo intensivo dos solos e principalmente em solos arenosos. $\mathrm{Na}$ maioria das formulações comerciais não se visa à restituição desses elementos, tendo-se observado uma sensível redução no rendimento de algumas culturas, principalmente quanto à deficiência de Boro (B) e Zinco (Zn). De acordo com Ceretta et al. (2005), as respostas a micronutrientes têm ocorrido com maior frequência nas condições de cerrado brasileiro. Neste contexto, a aplicação de fertilizantes foliares com micronutrientes tem aumentado nos últimos anos, em virtude, dentre outros fatores, da necessidade de se buscar altas produtividades das culturas.

A avaliação da qualidade fisiológica das sementes de soja é outro aspecto importante no manejo da cultura. Estas características são controladas geneticamente e, portanto, são fatores inerentes a cada genótipo; sendo preponderante em relação às práticas de manejo da 
cultura (KRZYZANOWSKI et al., 1993). O vigor influencia diretamente o desenvolvimento inicial da planta e pode ser influenciado pelo manejo da adubação na cultura e condições ambientais durante o desenvolvimento das sementes. Características como baixa porcentagem de germinação, maior susceptibilidade de sementes e mudas com crescimento lento, menor desenvolvimento radicular, estão associados a sementes que possuem um baixo potencial fisiológico. Em geral, o vigor das sementes inclui características que determinam o potencial para uma rápida e uniforme emergência de plântulas normais sob uma vasta gama de condições ambientais (MARCOS FILHO, 2005). Em trabalho conduzido por Dias et al. (2011), avaliando os efeitos diretos do vigor de sementes de soja sobre o rendimento de grãos, verificaram que as plantas provenientes do lote de sementes de alto vigor apresentam maior produtividade de grãos.

$\mathrm{Na}$ literatura são escassos trabalhos que avaliam a nutrição das culturas em campos para produção de sementes (CARVALHO e NAKAGAWA, 2000; KAPPES et al., 2008). Neste sentido, torna-se importante a realização de trabalhos que relacionem a adubação, a nutrição de plantas e a qualidade fisiológica de sementes a fim de maximizar a eficiência da produção das culturas nos diversos sistemas produtivos, principalmente no que concerne à aplicação de micronutrientes.

Desta forma, a presente pesquisa objetivou avaliar os teores foliares nutricionais, os componentes da produção e a produtividade de sementes da soja, além da sua qualidade fisiológica em função da adubação foliar com Boro e Zinco.

\section{MATERIAL E MÉTODOS}

O experimento foi conduzido na propriedade Sítio Vitória, situado no município de Vitória Brasil/SP, localizado entre 20¹1'34” de latitude sul e 50²9'30" de longitude oeste, com altitude de $489 \mathrm{~m}$. A precipitação anual média é de $1.221 \mathrm{~mm}$ e temperatura média anual de $24,4^{\circ} \mathrm{C}$. O clima da região, segundo a classificação de Köppen, é do tipo Aw, classificado como tropical úmido, com inverno seco e ameno e verão quente e chuvoso. Durante a condução do experimento foram coletados mensalmente, por meio de pluviômetro instalado na propriedade, os dados diários referentes a precipitação pluvial, conforme pode ser observado na Figura 1.

O solo onde foi instalado o experimento foi classificado como Argissolo VermelhoAmarelo eutrófico, abrúptico, horizonte A moderado, textura arenosa/média (SANTOS et al., 2006). Antes da instalação do experimento foi realizada a caracterização química do solo para fins de fertilidade, utilizando-se os métodos propostos por Raij et al. (2001). Foram coletadas 20 amostras de solo com estrutura deformada, realizadas com o auxílio de um trado de rosca na camada de 0,00-0,20 m. Essas amostras apresentaram: $\mathrm{pH}\left(\mathrm{CaCl}_{2} 0,01\right.$ mol L-1 ) 6,0; $16 \mathrm{~g} \mathrm{dm}^{-3}$ de M.O; 0 mmol $_{\mathrm{c}} \mathrm{dm}^{-3} \mathrm{de} \mathrm{Al} ; 31 \mathrm{mmol}_{\mathrm{c}} \mathrm{dm}^{-3} \mathrm{de} \mathrm{Ca} ; 23 \mathrm{mmol}_{\mathrm{c}} \mathrm{dm}^{-3}$ $\mathrm{Mg} ; 10 \mathrm{mmol}_{\mathrm{c}} \mathrm{dm}^{-3} \mathrm{de} \mathrm{H}+\mathrm{Al} ; 4,1 \mathrm{mmol}_{\mathrm{c}} \mathrm{dm}^{-3} \mathrm{de} \mathrm{K} ; 28 \mathrm{mg} \mathrm{dm}^{-3}$ de P resina; 58,1 $\mathrm{mmol}_{\mathrm{c}}$ $\mathrm{dm}^{-3}$ de SB; 68,1 $\mathrm{mmol}_{\mathrm{c}} \mathrm{dm}^{-3}$ de CTC; V\% de 85; 0,12 $\mathrm{mg} \mathrm{dm}^{-3}$ de B; 0,7 $\mathrm{mg} \mathrm{dm}^{-3}$ de Cu; $11 \mathrm{mg} \mathrm{dm}^{-3}$ de Fe; $20,5 \mathrm{mg} \mathrm{dm}^{-3}$ de $\mathrm{Mn}$ e $1,2 \mathrm{mg} \mathrm{dm}^{-3}$ de $\mathrm{Zn}$. 


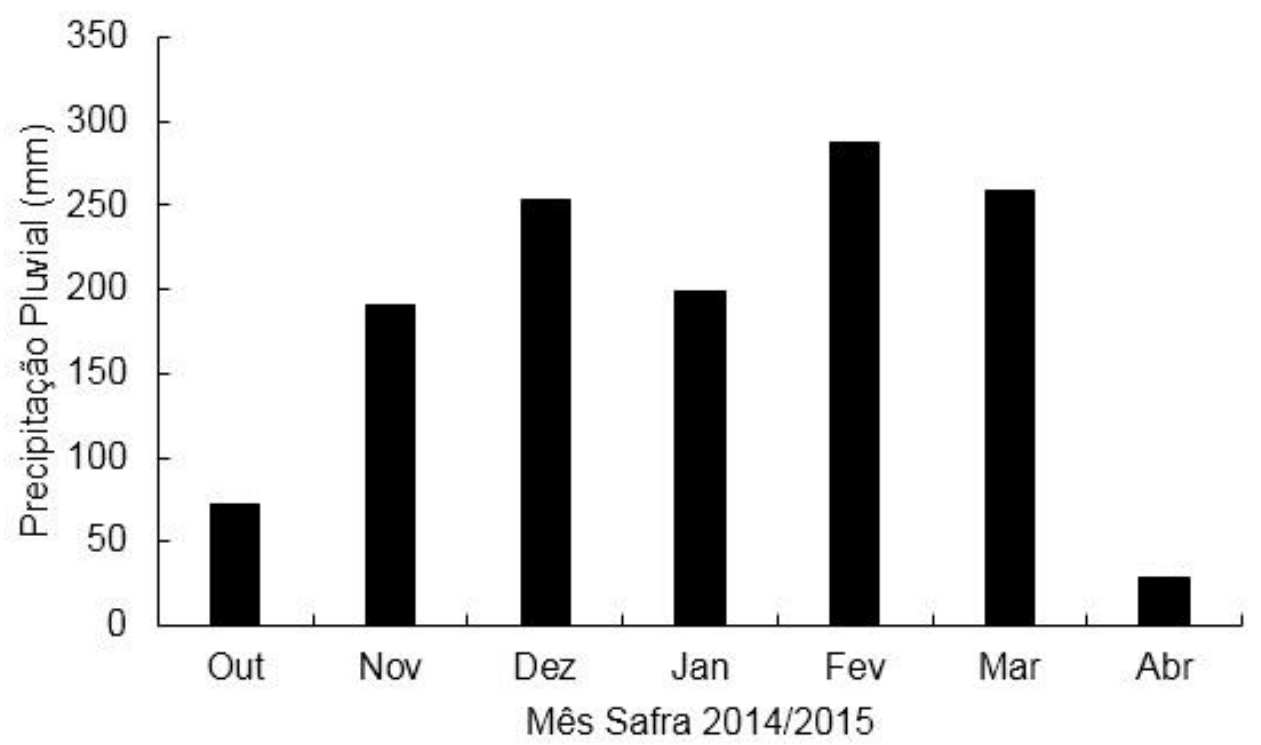

Figura 1. Precipitação pluvial durante os meses de outubro de 2014 a abril de 2015. Vitória Brasil - SP.

O delineamento experimental utilizado foi de blocos casualizados, sendo constituído por 10 tratamentos e 4 repetições. As parcelas experimentais foram compostas por 2,5 m de largura (6 linhas espaçadas por $0,50 \mathrm{~m}$ ) com $6 \mathrm{~m}$ de comprimento, totalizando $15 \mathrm{~m}^{2}$. As avaliações foram realizadas na área útil da parcela (3 linhas centrais com $4 \mathrm{~m}$ de comprimento).

Os tratamentos foram constituídos pela aplicação, via foliar, de diferentes combinações e dosagens de Boro (B) e Zinco (Zn) na cultura da soja. Os tratamentos foram compostos por: T1- Sem aplicação de Boro e Zinco (testemunha); T2 - Aplicação de $100 \mathrm{~g}$ ha $^{-1}$ de Boro ; T3 - Aplicação de $200 \mathrm{~g} \mathrm{ha}^{-1}$ de Zinco ; T4 - Aplicação de $100 \mathrm{~g} \mathrm{ha}^{-1}$ de Boro + $200 \mathrm{~g} \mathrm{ha}^{-1}$ de Zinco; T5 - Aplicação de $200 \mathrm{~g} \mathrm{ha}^{-1}$ de Boro ; T6 - Aplicação de $400 \mathrm{~g} \mathrm{ha}^{-1}$ de Zinco; T7 - Aplicação de $200 \mathrm{~g} \mathrm{ha}^{-1}$ de Boro + de $400 \mathrm{~g} \mathrm{ha}^{-1} \mathrm{e}$ Zinco; T8 - Aplicação de $400 \mathrm{~g} \mathrm{ha}^{-1}$ de Boro; T9 - Aplicação de $800 \mathrm{~g} \mathrm{ha}^{-1}$ de Zinco e T10 - Aplicação de $400 \mathrm{~g} \mathrm{ha}^{-1}$ de Boro + de $800 \mathrm{~g} \mathrm{ha}^{-1}$ e Zinco.

Antes da semeadura da cultura da soja, a área experimental estava sendo cultivada com a cultura do sorgo forrageiro cv. Volumax (Sorghum bicolor (L.) Moench). Após a dessecação das plantas presentes na área em 14/10/2014 com o herbicida Glyphosate (1.440 $\mathrm{g} \mathrm{ha}^{-1}$ do ingrediente ativo - i.a.) e posterior manejo com triturador horizontal de resíduos vegetais (Triton) em 19/10/2014, realizou-se a semeadura da cultura da soja no dia 06/11/2014, sobre a palhada de sorgo.

A soja cv. NS 7000 IPRO, foi semeada com uma semeadora-adubadora com mecanismo sulcador do tipo haste (facão) para SPD, em espaçamento de $0,50 \mathrm{~m} \mathrm{e}$ aproximadamente 12 sementes por metro de sulco, visando-se atingir um estande final de plantas próximo a 260.000 plantas $\mathrm{ha}^{-1}$. Momento antes da semeadura da cultura, as sementes foram inoculadas com Bradyrizobium japonicum turfoso (600.000 células viáveis semente $^{-1}$ ) e tratadas com $150 \mathrm{~g} \mathrm{~L}^{-1}$ i. a. imidacloprido $+450 \mathrm{~g} \mathrm{~L}^{-1}$ i. a. tiodicarbe. Aplicou- 
se ainda molibdênio e cobalto, na dose de $100 \mathrm{~mL} 100 \mathrm{~kg}^{-1}$ de semente. Como adubação de semeadura, aplicou-se $290 \mathrm{~kg} \mathrm{ha}^{-1}$ da fórmula 06-24-12.

Durante o ciclo vegetativo das plantas de soja, houve a necessidade de aplicação dos herbicidas Glyphosate na dose de $1.440 \mathrm{~g} \mathrm{ha}^{-1}$ do equivalente ácido, utilizando um volume de pulverização de $200 \mathrm{~L} \mathrm{ha}^{-1}$, para o controle de plantas daninhas. Verificou-se o ataque de pragas, principalmente da lagarta Helicoverpa (Helicoverpa armigera) e percevejos (Piezodorus guildinii e Euschistus heros). Portanto, durante todo o ciclo da cultura, efetuaram-se diversas aplicações de inseticidas, visando amenizar o ataque destes insetos. Em 23/12/14 aplicou-se $20 \mathrm{~g} \mathrm{ha}^{-1}$ i. a. cipermetrina (200 $\mathrm{mL} \mathrm{ha}^{-1}$ p. c.), em 12/01/15, 20/01/15 e 25/01/15 aplicou-se $108 \mathrm{~g} \mathrm{ha}^{-1}$ i. a. metomil $+20 \mathrm{~g} \mathrm{ha}^{-1} \mathrm{i}$. a. cipermetrina $+0,5 \%$ de óleo mineral (v/v) e em 03/02/15 aplicou-se 107,5 $\mathrm{g} \mathrm{ha}^{-1} \mathrm{i}$. a. metomil, respectivamente.

A aplicação de B e Zn, via foliar, foi realizada quando cultura da soja se encontrava no estádio vegetativo V6. Como fonte de B, utilizou-se o produto comercial Nano R1 Boro - AllPlant, com $10 \%$ de boro e densidade de $1,35 \mathrm{~g} \mathrm{~L}^{-1}$ e como fonte de $\mathrm{Zn}$ o produto Nano R1 Zinco - AllPlant, que possui 50\% de zinco e densidade de 2,00 $\mathrm{g} \mathrm{L}^{-1}$. A aplicação foliar foi realizada com o auxílio de um pulverizador costal de pressão constante $\left(\mathrm{CO}_{2}\right)$, com ponta de jato tipo cone e vazão de $120 \mathrm{~L} \mathrm{ha}^{-1}$.

Por ocasião do florescimento da cultura da soja (R1), foram coletados, em cerca de 20 plantas/parcela, o terceiro trifólio completamente desenvolvido, à partir do ápice da planta. Estes trifólios foram coletados para determinação dos teores nutricionais $(\mathrm{N}, \mathrm{P}, \mathrm{K}, \mathrm{Ca}, \mathrm{Mg}$, $\mathrm{S}, \mathrm{B}, \mathrm{Cu}, \mathrm{Fe}, \mathrm{Mn}$ e $\mathrm{Zn}$ ) conforme metodologia descrita em Malavolta et al. (1997). Para tanto, as folhas foram submetidas à secagem em estufa de ventilação forçada à temperatura média de $65^{\circ} \mathrm{C}$ até atingir massa constante, e posteriormente moídas em moinho tipo Willey para determinação dos teores nutricionais.

A colheita da cultura da soja foi realizada em 06/03/2015, correspondendo a 115 dias após a emergência (DAE), neste momento, determinaram-se os componentes da produção e produtividade de grãos da cultura. Foram coletadas 10 plantas aleatoriamente por unidade experimental (área útil da parcela) e determinaram-se a altura de plantas (ALTP) e a altura de inserção da primeira vagem (AIPV) com o auxílio de uma régua graduada; o número total de vagens por planta (NVP), de sementes por planta (NSP), o número médio de sementes por vagem (NSV) e a massa de 100 sementes (M100) (13\% de base úmida). Determinou-se a produtividade de sementes (PS), colhendo-se todas as plantas da área útil da parcela experimental, as quais foram trilhadas mecanicamente e posteriormente à pesagem das sementes, os valores foram expressos em $\mathrm{kg} \mathrm{ha}^{-1}$ (13\% de umidade).

Para a qualidade fisiológica das sementes, foram coletadas as sementes de 20 plantas, colhidas aleatoriamente por parcela. Para tanto realizou-se os seguintes testes:

Comprimento da plântula (CP) e massa seca da plântula (MSP): a avaliação do CP e MSP foram realizadas a partir de quatro subamostras de 20 sementes para cada tratamento. Utilizou-se como substrato rolo de papel tipo germitest, no qual as sementes foram distribuídas em duas linhas retas longitudinais. Após a confecção dos rolos, os mesmos 
foram embalados em sacos plásticos e colocados em germinador regulado a temperatura constante de $25^{\circ} \mathrm{C}$ (NAKAGAWA, 1999). No $5^{\circ}$ dia após a instalação do teste, foi avaliado o CP e MSP das plântulas germinadas, sendo cada plântula medida separadamente.

Condutividade elétrica (CE): a determinação da condutividade elétrica foi realizada utilizando-se quatros amostras de 25 sementes. As amostras foram pesadas em balança de precisão e a seguir colocadas para embebição em recipiente plástico contendo $75 \mathrm{~mL}$ de água destilada, sendo mantidas em câmara-germinador à temperatura de $25^{\circ} \mathrm{C}$, durante $24 \mathrm{~h}$ (MARCOS FILHO, 2005). Após esse período, procedeu-se a leitura da condutividade elétrica na solução de embebição, utilizando-se um condutivímetro digital, cujos resultados foram expressos em $\mu \mathrm{S} \mathrm{cm}^{-1} \mathrm{~g}^{-1}$.

Envelhecimento acelerado (EA): foi conduzido com quatro subamostras de 50 sementes. Foram utilizadas caixas plásticas transparentes com tampa (gerbox) com 11 x 11 x $3 \mathrm{~cm}$, adaptadas como minicâmaras, dentro das quais foram adicionados $40 \mathrm{~mL}$ de água destilada. Acima da água foi colocada uma tela e sobre a tela, em cada caixa, foram colocadas as sementes. Em seguida, as caixas plásticas foram levadas para a câmara do tipo $\mathrm{BOD}$, regulada na temperatura de $42^{\circ} \mathrm{C}$, onde permaneceram por 48 horas (MARCOS FILHO, 2005). Após esse período, as sementes foram colocadas para germinar conforme descrito no teste de germinação, e a contagem do número de plântulas normais foi realizada no quinto dia após a instalação do teste. Os resultados foram expressos em porcentagem de plântulas normais.

Germinação $(\mathrm{G})$ : foi realizado segundo as Regras para Análise de Sementes (BRASIL, 2009), com quatro subamostras de 50 sementes, utilizando-se como substrato rolo de papel tipo germitest, umedecido com água destilada na proporção de 2,5 vezes sua massa seca. Após a confecção dos rolos, estes foram embalados em sacos plásticos e mantidos em câmara de germinação, à temperatura constante de $25^{\circ} \mathrm{C}$. A contagem foi realizada oito dias após a instalação do teste e os resultados expressos em porcentagem de plântulas normais.

Os resultados foram submetidos à análise de variância pelo teste $\mathrm{F}$ e quando significativos $(\mathrm{p} \leq 0,05)$ as médias foram comparadas pelo teste de Tukey $(\mathrm{p} \leq 0,05)$. As análises estatísticas foram realizadas utilizando o software SISVAR® (FERREIRA, 2011).

\section{RESULTADOS E DISCUSSÃO}

A análise dos teores de nutrientes foliares na soja é um dos métodos mais eficientes para avaliar o estado nutricional da cultura e a disponibilidade dos nutrientes no solo. Houve efeito significativo do uso de diferentes combinações e dosagens de B e Zn, aplicados via foliar na cultura da soja, somente sobre os teores nutricionais de potássio $(\mathrm{K})$ e enxofre $(\mathrm{S})$ foliares (Tabela 1). Para os teores de K, o tratamento T9 (800 $\mathrm{g} \mathrm{ha}^{-1}$ de $\mathrm{Zn}$ ) proporcionou resultados superiores aos tratamentos $\mathrm{T} 4$ (100 $\mathrm{g} \mathrm{ha}^{-1}$ de B e $200 \mathrm{~g} \mathrm{ha}^{-1} \mathrm{de} \mathrm{Zn}$ ) e T10 (400 g $\mathrm{ha}^{-1}$ de B e $800 \mathrm{~g} \mathrm{ha}^{-1} \mathrm{Zn}$ ), respectivamente. De acordo com Fernandes et al. (2007), apontam que o $\mathrm{K}$ com o $\mathrm{Zn}$, apresenta inibição competitiva pelos mesmos sítios de 
absorção, onde no trabalho não houve concordância para os resultados. Entretanto, torna-se importante destacar que os teores foliares de $\mathrm{K}$ em todos os tratamentos, permaneceram dentro da faixa considerada adequada (22-25 $\mathrm{g} \mathrm{kg}^{-1}$ ) para o bom desenvolvimento da soja (MALAVOLTA, 2006).

Tabela 1. Teores de macronutrientes em folhas de soja em função de diferentes combinações e dosagens de Boro e Zinco, aplicados via foliar. Vitória Brasil, SP. Safra de $2014 / 2015$.

\begin{tabular}{|c|c|c|c|c|c|c|}
\hline Tratamentos & $\mathrm{N}$ & $\mathrm{P}$ & $\mathrm{K}$ & $\mathrm{Ca}$ & $\mathrm{Mg}$ & $\mathrm{S}$ \\
\hline $\mathrm{T} 1$ & 43,12 & 3,45 & $23,52 \mathrm{ab}$ & 6,85 & 3,89 & $1,84 \mathrm{ab}$ \\
\hline $\mathrm{T} 2$ & 45,51 & 3,85 & $24,55 \mathrm{ab}$ & 6,88 & 4,19 & $2,00 \mathrm{ab}$ \\
\hline $\mathrm{T} 3$ & 43,01 & 3,32 & $23,85 \mathrm{ab}$ & 7,64 & 3,91 & $1,96 \mathrm{ab}$ \\
\hline $\mathrm{T} 4$ & 42,71 & 3,60 & $22,69 \mathrm{~b}$ & 7,27 & 4,13 & $2,09 \mathrm{ab}$ \\
\hline $\mathrm{T} 5$ & 46,11 & 3,85 & $23,18 \mathrm{ab}$ & 7,39 & 4,08 & $2,20 \mathrm{a}$ \\
\hline T6 & 43,31 & 3,97 & $23,29 \mathrm{ab}$ & 7,00 & 4,01 & $1,65 \mathrm{~b}$ \\
\hline $\mathrm{T} 7$ & 42,73 & 4,78 & $26,23 \mathrm{ab}$ & 7,40 & 4,08 & $1,42 \mathrm{c}$ \\
\hline T8 & 44,57 & 4,18 & $23,09 \mathrm{ab}$ & 6,87 & 4,02 & $1,56 \mathrm{bc}$ \\
\hline T9 & 42,35 & 4,61 & $27,79 \mathrm{a}$ & 7,38 & 4,37 & $1,67 \mathrm{~b}$ \\
\hline T10 & 47,11 & 4,21 & $22,01 \mathrm{~b}$ & 6,46 & 4,02 & $1,50 \mathrm{bc}$ \\
\hline DMS & 7,16 & 1,58 & 4,99 & 1,53 & 0,73 & 0,61 \\
\hline $\mathrm{CV}(\%)$ & 6,68 & 16,39 & 8,54 & 8,86 & 7,40 & 14,20 \\
\hline Valores de F & $1,27 \mathrm{~ns}$ & $2,11 \mathrm{~ns}$ & $2,91 *$ & $1,28 \mathrm{~ns}$ & $0,85 \mathrm{~ns}$ & $4,39 * *$ \\
\hline
\end{tabular}

Médias seguidas pela mesma letra na coluna, não diferem entre si pelo teste de Tukey a 5\% de probabilidade. ** e *: significativo ao nível de 1 e 5\% respectivamente. ns: não significativo. Em que: CV: coeficiente de variação; DMS: diferença mínima significativa.

Da mesma forma, o teor foliar de $\mathrm{S}$ foi maior para o tratamento T5 (200 $\mathrm{g} \mathrm{ha}^{-1}$ de B), comparado a aplicação de $\mathrm{B}$ e $\mathrm{Zn}$ de forma combinada, principalmente no tratamento T7 (200 $\mathrm{g} \mathrm{ha}^{-1}$ de B e $400 \mathrm{~g} \mathrm{ha}^{-1} \mathrm{Zn}$ ) (Tabela 1). Ressalta-se que o teor de $\mathrm{S}$ na folha diagnóstico esteve abaixo dos valores considerados adequados pela faixa de interpretação $(2,5-3,5 \mathrm{~g}$ $\mathrm{kg}^{-1}$ ) de acordo com Malavolta (2006), principalmente para os tratamentos T4 e T5. Tal resultado pode ser atribuído à textura arenosa do solo, que aliado ao baixo teor de matéria orgânica (MO) (16 $\mathrm{g} \mathrm{dm}^{-3}$ ) e ausência de adubação mineral com fertilizantes contendo S em sua formulação, ocasionaram um baixo teor foliar deste elemento. De acordo com Mengel e kirkby (1979) e Blakesley et al. (1991), o zinco é fundamental na síntese do triptofano, um precursor do Ácido Indol-3 Ácetico, que é um fito-hormônio envolvido na formação de raízes, sendo uma das hipóteses para que o $\mathrm{S}$ faça parte deste aminoácido precursor de auxinas importantes no alongamento dos tecidos e crescimento vegetal. Entretanto, cabe ressaltar que este fato não causou prejuízos ao adequado desenvolvimento da cultura da soja nas condições em que foram realizadas a presente pesquisa, além das plantas não terem apresentado sintomas de deficiência foliar. 
De maneira geral, as diferentes combinações e dosagens de $\mathrm{B}$ e $\mathrm{Zn}$, aplicados via foliar na cultura da soja, não influenciaram significativamente os teores foliares de $\mathrm{N}, \mathrm{P}, \mathrm{Ca}$ e Mg (Tabela 1). Contudo, deve-se destacar que os valores para estes elementos ficaram dentro da faixa adequada para a cultura da soja (MALAVOLTA, 2006), garantindo assim, o bom desenvolvimento das plantas. Segundo Taiz e Zaiger (2009), o equilíbrio nutricional das plantas é o fator primordial, interferindo diretamente no desenvolvimento da cultura. De acordo com este autor, para a cultura da soja, as faixas ideias para os macronutrientes encontram-se entre $55-58 \mathrm{~g} \mathrm{~kg}^{-1}$ para o $\mathrm{N}$, de $4-5 \mathrm{~g} \mathrm{~kg}^{-1}$ para o $\mathrm{P}$, de $22-25 \mathrm{~g} \mathrm{~kg}^{-1}$ para o K, de 9-10 $\mathrm{g} \mathrm{kg}^{-1}$ para o $\mathrm{Ca}$, de 3,5-4,0 $\mathrm{g} \mathrm{kg}^{-1}$ par ao $\mathrm{Mg}$ e de 2,5-3,5 $\mathrm{g} \mathrm{kg}^{-1}$ para o $\mathrm{S}$, com vistas a melhor entender ou interpretar os resultados da diagnose foliar.

Para os teores foliares de micronutrientes, também se verificou que a aplicação de B e Zn não proporcionou diferenças significativas para os teores foliares dos micronutrientes avaliados (Tabela 2). Um fator relevante que deve ser observado para o não aumento das concentrações de micronutrientes nas folhas, é a baixa mobilidade de B e Zn na planta (MALAVOLTA, 2006). Segundo Boaretto et al. (1997), muitas vezes a não associação entre os aumentos dos teores de boro nas folhas pode ser esclarecida pela dificuldade da planta em retirar esse nutriente retido na cutícula foliar ou aquele ligado à camada péctica da parede celular e transferir para as folhas.

Tabela 2. Teores de micronutrientes em folhas de soja em função de diferentes combinações e dosagens de Boro e Zinco, aplicados via foliar. Vitória Brasil, SP. Safra de $2014 / 2015$.

\begin{tabular}{cccccc}
\hline \multirow{2}{*}{ Tratamentos } & B & $\mathrm{Cu}$ & $\mathrm{Fe}$ & $\mathrm{Mn}$ & $\mathrm{Zn}$ \\
& ---------------------- \\
\hline T1 & 60,68 & 20,25 & 116,75 & 80,75 & 44,50 \\
T2 & 63,40 & 16,00 & 131,75 & 82,50 & 50,00 \\
T3 & 55,00 & 16,00 & 118,50 & 76,50 & 41,25 \\
T4 & 62,34 & 8,50 & 118,25 & 77,00 & 42,25 \\
T5 & 59,85 & 26,50 & 132,25 & 79,75 & 44,75 \\
T6 & 59,98 & 12,25 & 131,50 & 76,25 & 47,25 \\
T7 & 65,69 & 24,25 & 134,00 & 77,25 & 45,75 \\
T8 & 66,01 & 14,00 & 129,25 & 87,25 & 49,25 \\
T9 & 63,78 & 10,75 & 140,75 & 83,00 & 52,25 \\
T10 & 65,46 & 31,50 & 147,00 & 83,50 & 49,50 \\
\hline DMS & 15,01 & 26,75 & 51,80 & 21,62 & 18,84 \\
\hline CV $(\%)$ & 9,92 & 61,09 & 16,38 & 11,06 & 16,39 \\
\hline Valores de F & $1,24 \mathrm{~ns}$ & $1,83 \mathrm{~ns}$ & $0,86 \mathrm{~ns}$ & $0,68 \mathrm{~ns}$ & $1,35 \mathrm{~ns}$ \\
\hline
\end{tabular}

Médias seguidas pela mesma letra na coluna, não diferem entre si pelo teste de Tukey a 5\% de probabilidade. ** e *: significativo ao nível de 1 e $5 \%$ respectivamente. ${ }^{\text {ns: }}$ não significativo. Em que: CV: coeficiente de variação; DMS: diferença mínima significativa.

$\mathrm{Na}$ presente pesquisa, o fornecimento dos elementos $\mathrm{B}$ e $\mathrm{Zn}$ às plantas foi realizado via pulverização foliar, o que pode ter promovido a não atuação dos nutrientes nos tecidos 
foliares das plantas, não participando significativamente dos processos de acúmulo de micronutrientes na folha. Entretanto, os teores de $\mathrm{Cu}, \mathrm{Fe}, \mathrm{Mn}$ e $\mathrm{Zn}$ nas folhas ficaram dentro das faixas consideradas adequadas para a cultura (MALAVOLTA, 2006).

Para a concentração de $\mathrm{B}$, os valores ficaram acima do recomendado (21 a $\left.55 \mathrm{~g} \mathrm{~kg}^{-1}\right)$ mesmo para o tratamento testemunha (T1). Tal fato pode ser atribuído à matéria orgânica do solo, que apesar de ser considerada como de baixo teor no solo da presente pesquisa, de acordo com Embrapa (2006), pode ter fornecido quantidade satisfatória do nutriente para o adequado desenvolvimento da soja. Os resíduos vegetais de sorgo, utilizados como palhada para semeadura da soja em sucessão, também pode ter auxiliado no processo de nutrição da cultura, através da decomposição e mineralização dos resíduos vegetais.

Sendo assim, é de extrema relevância avaliar-se o estado nutricional da cultura da soja, principalmente quando são fornecidos fontes de nutrientes e quando a cultura é semeada sobre palhada de espécies gramíneas com alta relação $\mathrm{C} / \mathrm{N}$, como no caso da presente pesquisa, o sorgo forrageiro.

De acordo com Costa et al. (2015), a palhada de sorgo forrageiro é uma excelente opção para o cultivo da cultura da soja, promovendo boas condições ao desenvolvimento das plantas, além de altas produtividades de grãos. Na presente pesquisa ficou evidenciado que a palhada de sorgo cultivado em antecessão à soja (cuja quantidade de palhada no momento da semeadura da soja foi de aproximadamente 4,5 $\mathrm{t} \mathrm{ha}^{-1}$ ), o adequado fornecimento de nutrientes via adubação mineral de semeadura, ambos aliados ao fornecimento de $\mathrm{B}$ e $\mathrm{Zn}$ via foliar foram eficientes em promover a adequada nutrição da cultura e ainda garantir o bom desenvolvimento das plantas.

A determinação das características quantitativas como os componentes da produção (número de vagens por planta, número de sementes por vagem e massa das sementes) e produtividade de sementes, são extremamente importantes, uma vez que estes parâmetros são os mais influenciados pelo manejo da cultura. Sendo assim, verificou-se que as diferentes combinações e dosagens de B e $\mathrm{Zn}$ aplicados via foliar na cultura da soja, não influenciaram o crescimento (ALTP e AIPV), os componentes da produção (NVP, NSP, NSV e M100) e produtividade de sementes (PS) da cultura (Tabela 3).

Os valores obtidos para ALTP, assim como a AIV, são de elevada importância, tendo em vista que estas características auxiliam no melhor rendimento na operação de colheita da cultura. Os componentes da produção e produtividade de sementes verificados na presente pesquisa (Tabela 3), foram semelhantes aos obtidos por Costa et al., (2015), em cultivo da soja sobre palhada de sorgo forrageiro, em região próxima à do presente estudo e em condições irrigadas, demonstrando a viabilidade de produção da cultura da soja sob plantio direto na região.

Em função das condições edafoclimáticas e do correto manejo da cultura, a PS verificada em todos os tratamentos pode ser considerada elevada para a região (Tabela 3). De modo geral, a produtividade de grãos de soja sempre foi superior a $3.000 \mathrm{~kg} \mathrm{ha}^{-1}$, valores estes próximos à média de produtividade brasileira para a safra 2014/2015 de $3.033 \mathrm{~kg} \mathrm{ha}^{-1}$ 
(CONAB, 2015). Costa et al., (2015), avaliando os componentes da produção e produtividade de grãos da soja cultivada em sucessão a diferentes espécies forrageiras \{sorgo forrageiro (Sorghum bicolor (L.) Moench), milheto (Pennisetum glaucum (L.) R. Br.) e capim Xaraés (Urochloa brizantha) \}, verificaram que a maior produtividade de grãos da soja foi obtida quando esta foi cultivada sob palhada de sorgo forrageiro, com valores de $2.793 \mathrm{~kg} \mathrm{ha}^{-1}$ (safra 2009/2010) e de $2.801 \mathrm{~kg} \mathrm{ha}^{-1}$ (safra 2010/2011), respectivamente, sendo esta considerada ainda uma atividade lucrativa (COSTA et al., 2013).

Tabela 3. Altura de plantas (ALTP), altura de inserção da primeira vagem (AIPV), número de vagens por planta (NVP), de sementes por planta (NSP), de sementes por vagem (NSV), massa de 100 sementes (M100) e produtividade de sementes (PS) da cultura da soja em função de diferentes combinações e dosagens de Boro e Zinco, aplicados via foliar. Vitória Brasil, SP. Safra de 2014/2015.

\begin{tabular}{|c|c|c|c|c|c|c|c|}
\hline \multirow[t]{2}{*}{ Tratamentos } & ALTP & AIPV & NVP & NSP & NSV & \multirow{2}{*}{$\begin{array}{c}\text { M100 } \\
\mathrm{g} \\
\end{array}$} & \multirow{2}{*}{$\begin{array}{c}\text { PS } \\
\mathrm{kg} \mathrm{ha}^{-1}\end{array}$} \\
\hline & \multicolumn{2}{|c|}{--------cm--------- } & \multicolumn{3}{|c|}{ - } & & \\
\hline $\mathrm{T} 1$ & 92,75 & 20,50 & 28,75 & 69,05 & 2,39 & 20,91 & 3.065 \\
\hline $\mathrm{T} 2$ & 70,80 & 20,12 & 36,05 & 85,85 & 2,39 & 20,09 & 3.071 \\
\hline $\mathrm{T} 3$ & 93,17 & 18,90 & 35,90 & 79,40 & 2,21 & 20,04 & 3.463 \\
\hline $\mathrm{T} 4$ & 93,12 & 18,45 & 40,35 & 99,60 & 2,47 & 21,54 & 3.385 \\
\hline T5 & 99,15 & 20,50 & 39,90 & 100,00 & 2,48 & 20,96 & 3.226 \\
\hline T6 & 96,76 & 19,40 & 46,20 & 115,25 & 2,50 & 22,28 & 3.050 \\
\hline $\mathrm{T} 7$ & 97,00 & 18,75 & 41,20 & 92,95 & 2,18 & 20,26 & 3.140 \\
\hline $\mathrm{T} 8$ & 92,45 & 18,85 & 46,25 & 107,65 & 2,42 & 21,33 & 3.102 \\
\hline T9 & 95,40 & 19,10 & 43,10 & 96,90 & 2,24 & 21,32 & 2.944 \\
\hline T10 & 95,10 & 19,85 & 43,05 & 113,80 & 2,67 & 21,13 & 3.084 \\
\hline $\mathrm{CV}(\%)$ & 12,95 & 12,05 & 19,85 & 20,79 & 14,28 & 5,96 & 10,71 \\
\hline Teste F & $1,76 \mathrm{~ns}$ & $0,41 \mathrm{~ns}$ & $1,80 \mathrm{~ns}$ & $2,19 \mathrm{~ns}$ & $0,76 \mathrm{~ns}$ & $1,26 \mathrm{~ns}$ & $0,90 \mathrm{~ns}$ \\
\hline
\end{tabular}

Médias seguidas das mesmas letras minúsculas nas colunas não diferem pelo teste de Tukey a $5 \%$ de probabilidade.

As respostas à aplicação de micronutrientes têm sido mais frequentes nas condições do Cerrado, devido à baixa fertilidade natural dos solos e das condições edafoclimáticas característicos da região. Broch e Fernandes (1999) mostraram que na média de 12 estudos com micronutrientes aplicados via sementes, houve aumento de até 6,5 sacas ha ${ }^{-1}$ na produtividade da soja. Ceretta et al. (2005) avaliando a viabilidade técnica e econômica da aplicação de alguns micronutrientes na produtividade de grãos da soja, verificaram que na maioria dos casos, o retorno econômico da aplicação dos micronutrientes utilizados foi positivo.

Em trabalho realizado por Bevilaqua et al. (2002), os autores verificaram que a aplicação via foliar de Ca e B aumentou o peso de grãos por planta de soja em solos de várzea no Rio Grande do Sul, proporcionando melhor produtividade de grãos. Kappes et al. (2008), avaliando doses e épocas de aplicação de B, via foliar na cultura da soja, variedade M-SOY 8411, obtiveram produtividade média de grãos próxima a $3.500 \mathrm{~kg} \mathrm{ha}^{-1}$, entretanto, 
os autores verificaram que os tratamentos não influenciaram a produtividade de grãos e a qualidade fisiológica das sementes de soja.

Souza et al. (2008) avaliando os componentes de rendimento de variedades de soja em função da aplicação foliar de $\mathrm{Ca}$ e B, em duas fases reprodutivas da cultura, verificaram que a aplicação destes nutrientes proporcionou maior produtividade na soja, com valores variando entre $2.003 \mathrm{~kg} \mathrm{ha}^{-1}$ para a cv. BRS Favorita a $6.506 \mathrm{~kg} \mathrm{ha}^{-1}$ para a cv. BRS-MG RR em condições de cerrado. Gonçalves Júnior et al. (2010), avaliando a resposta de plantas de soja ao $\mathrm{Zn}$ em relação a diferentes doses de fósforo $(\mathrm{P})$ e potássio $(\mathrm{K})$, verificaram que as doses de Zn, não interferiram na produtividade ou nos componentes de produção da cultura.

A prática da adubação foliar tem sido amplamente recomendada para aumentar ou manter a concentração de nutrientes nas folhas, no período de enchimento de grãos, uma vez que neste período a absorção de nutrientes pelas raízes é muito baixa (TAIZ e ZEIGER, 2009). Através desta prática, pode-se então aumentar o conteúdo de nutrientes na planta e o metabolismo formador de estruturas reprodutivas promovendo consequentemente o aumento na produtividade de grãos da cultura (HARTER e BARROS, 2011).

O comprimento de plântulas (CP), massa seca de plântulas (MSP), condutividade elétrica (CE) e envelhecimento acelerado (EA) foram influenciados significativamente pelas diferentes combinações e dosagens de B e Zn, aplicados via foliar na cultura da soja (Tabela 4). Os menores valores para $\mathrm{CP}$ foram obtidos nos tratamentos $\mathrm{T} 3$ e $\mathrm{T} 6$, assim como para MSP no T3, apesar de serem valores próximos entre si. Para CE, os menores valores foram verificados no tratamento T4 e para EA, nos tratamentos T2, T3 e T10. Entretanto, cabe-se ressaltar que, de maneira geral, todos os tratamentos avaliados proporcionaram boa qualidade fisiológica das sementes de soja, apesar da diferença estatística.

De modo geral, a qualidade fisiológica das sementes de soja foi influenciada estatisticamente pelos tratamentos. Entretanto, cabe-se ressaltar que, embora tenha-se observado melhora significativa em função do fornecimento de B e $\mathrm{Zn}$ via foliar em alguns tratamentos, a testemunha (T1) proporcionou sementes com qualidade semelhante. O CP e MSP permaneceram com valores adequados e estão de acordo com o reportado na literatura (SÁ e LAZARINI, 1995; BEVILAQUA et al., 2002; TOLEDO et al., 2012). Por outro lado, em trabalho realizado por Bevilaqua et al. (2002), os autores não verificaram diferença significativa na massa da matéria seca de plântulas de duas cultivares de soja em função de doses de cálcio e boro.

A condutividade elétrica (CE), avalia a integridade das membranas quanto à permeabilidade seletiva. Os resultados obtidos na presente pesquisa para este parâmetro podem ser considerados elevados, entretanto não verificou-se influencia deste fator no vigor das sementes de soja (Tabela 4). Os menores valores de condutividade elétrica podem indicar sementes com menores danos nas suas membranas. De acordo com Vazquez et al. (2008), os resultados obtidos na presente pesquisa podem caracterizar as sementes como de alto vigor, trabalhando com as cultivares BRSMG 68 Vencedora e M-SOY 8001. Em trabalho realizado por Sá e Lazarini (1995), os autores verificaram que em sementes com 
condutividade elétrica abaixo de $60 \mu \mathrm{S} \mathrm{cm}^{-1} \mathrm{~g}^{-1}$ houve alta porcentagem de emergência no solo, germinação e vigor. Contudo, Marcandalli et al. (2011) verificaram uma alta porcentagem de germinação, mesmo com valores de condutividade elétrica próximos a 100 $\mu \mathrm{S} \mathrm{cm}^{-1} \mathrm{~g}^{-1}$, assim como o verificado na presente pesquisa.

Tabela 4. Comprimento de plântulas (CP), massa seca de plântulas (MSP), condutividade elétrica (CE), envelhecimento acelerado (EA) e germinação (G), em sementes de soja em função de diferentes combinações e dosagens de Boro e Zinco, aplicados via foliar. Vitória Brasil, SP. Safra de 2014/2015.

\begin{tabular}{|c|c|c|c|c|c|}
\hline \multirow{2}{*}{ Tratamentos } & $\mathrm{CP}$ & \multirow{2}{*}{$\begin{array}{c}\text { MSP } \\
\text { mg.plântula }{ }^{-1}\end{array}$} & \multirow{2}{*}{$\begin{array}{c}\mathrm{CE} \\
\mu \mathrm{S} \mathrm{cm}^{-1} \mathrm{~g}^{-1}\end{array}$} & EA & \multirow[t]{2}{*}{$\mathrm{G}$} \\
\hline & $\mathrm{cm}$ & & & ---------. & \\
\hline $\mathrm{T} 1$ & $12,75 \mathrm{a}$ & $25,04 \mathrm{ab}$ & $81,36 \mathrm{a}$ & $61,00 \mathrm{ab}$ & 97,50 \\
\hline $\mathrm{T} 2$ & $13,20 \mathrm{a}$ & $27,36 \mathrm{ab}$ & $83,28 \mathrm{a}$ & $49,00 \mathrm{c}$ & 97,00 \\
\hline $\mathrm{T} 3$ & $10,72 b$ & $23,45 b$ & $75,86 \mathrm{ab}$ & $33,00 \mathrm{c}$ & 94,00 \\
\hline $\mathrm{T} 4$ & $14,75 \mathrm{a}$ & $27,83 \mathrm{ab}$ & $61,79 \mathrm{~b}$ & $73,00 \mathrm{a}$ & 97,50 \\
\hline T5 & $12,92 \mathrm{a}$ & $27,15 \mathrm{ab}$ & $74,12 \mathrm{ab}$ & $55,00 \mathrm{~b}$ & 98,00 \\
\hline T6 & $11,87 \mathrm{~b}$ & $26,52 \mathrm{ab}$ & $79,64 \mathrm{ab}$ & $53,50 \mathrm{~b}$ & 94,50 \\
\hline $\mathrm{T} 7$ & $13,47 \mathrm{a}$ & $26,24 \mathrm{ab}$ & $76,92 \mathrm{ab}$ & $84,00 \mathrm{a}$ & 99,00 \\
\hline $\mathrm{T} 8$ & $12,70 \mathrm{a}$ & $25,53 \mathrm{ab}$ & $85,22 \mathrm{a}$ & $69,00 \mathrm{ab}$ & 96,50 \\
\hline T9 & $12,22 \mathrm{a}$ & $31,98 \mathrm{a}$ & $79,88 \mathrm{ab}$ & $64,00 \mathrm{ab}$ & 95,00 \\
\hline $\mathrm{T} 10$ & $12,07 \mathrm{a}$ & $25,45 \mathrm{ab}$ & 85,66 a & $50,50 \mathrm{c}$ & 96,00 \\
\hline CV (\%) & 10,70 & 11,21 & 9,60 & 22,41 & 2,76 \\
\hline Teste F & $2,48 *$ & $2,30 *$ & $3,44 * *$ & $4,62 * *$ & $1,37 \mathrm{~ns}$ \\
\hline
\end{tabular}

Médias seguidas por mesma letra na coluna, para diferentes tratamentos, não diferem entre si pelo teste de Tukey a $5 \%$ de probabilidade. ${ }^{* *}$ e *: significativo a 1 e $5 \%$ de probabilidade pelo Teste de Tukey, respectivamente. ${ }^{\text {ns }}$ não significativo. Em que: DMS: diferença mínima significativa e CV: coeficiente de variação.

O teste de envelhecimento acelerado (EA) é um método eficiente para avaliar o potencial fisiológico de sementes de soja, pois está associado com a deterioração das sementes. Na presente pesquisa, apesar da diferença significativa para o EA em função dos tratamentos (Tabela 4), pode-se classificar as sementes de soja como sendo de alto potencial fisiológico, uma vez que em todos os tratamentos obteve-se germinação superior a $90 \%$.

A porcentagem de germinação $(\mathrm{G})$ não foi influenciada pelos tratamentos, apresentando ainda valores elevados, inclusive na testemunha (T1) (Tabela 4). Verificou-se ainda que os valores obtidos na presente pesquisa, em média, classificam a produção obtida como adequada para a comercialização como semente, pois conforme Brasil (2005), a porcentagem mínima exigida como padrão para semente é de $80 \%$.

De modo geral, as condições edafoclimáticas e o adequado fornecimento de nutrientes à cultura da soja na presente pesquisa (adubação de semeadura e aplicação de $\mathrm{B}$ e $\mathrm{Zn}$ via foliar), favoreceram a obtenção de sementes com boa qualidade fisiológica. Em virtude de tal fato, houve melhor condição de nutrição da planta, com formação de uma semente mais resistente, reduzindo a deterioração, o que foi confirmado pelo teste de germinação (Tabela 
4). Os resultados obtidos na presente pesquisa estão de acordo com os verificados por vários autores avaliando estes mesmos parâmetros na cultura da soja (VIEIRA, 1994; BEVILAQUA et al., 2002; KAPPES et al., 2008; VASQUEZ et al., 2008; DIAS et al., 2011; HARTER e BARROS, 2011; MARCANDALLI et al., 2011; TOLEDO et al., 2012).

De acordo com Costa et al. (2003), as sementes contêm genes que expressam o potencial produtivo da cultivar utilizada, uma vez que a elevada qualidade fisiológica implica numa série de características economicamente desejáveis como sanidade, adaptação às condições adversas de clima e solo, assim como maior capacidade de germinação. Entretanto, o correto manejo da cultura, assim como os fatores abióticos durante seu desenvolvimento são determinantes na adequada nutrição e produção da cultura, resultados estes comprovados na presente pesquisa.

De acordo com Krzyzanowski et al. (1993), caracteres da planta, da vagem, da própria semente de soja e seus efeitos interativos podem estar relacionados com a deterioração das sementes, determinando o comportamento diferencial entre genótipos e seu grau de tolerância à deterioração das sementes em função das condições de campo e da colheita mecanizada. Desta forma, a qualidade das sementes é um parâmetro de extrema relevância nos sistemas produtivos pois irá refletir diretamente no resultado final da cultura, proporcionando uniformidade de população, elevado vigor das plantas, ausência de doenças transmitidas via semente e, por conseguinte, maior produtividade.

Pode-se considerar, portanto, que os teores nutricionais foliares, a qualidade fisiológica das sementes e os valores para os componentes da produção e produtividade de sementes da cultura foram satisfatórios para o cultivar de soja utilizado, demonstrando a eficácia do manejo adotado durante o desenvolvimento da cultura e das boas condições edafoclimáticas da área de cultivo. Entretanto, verifica-se que os trabalhos encontrados na literatura são bastante controversos com relação aos efeitos da aplicação de micronutrientes, principalmente B e Zn na qualidade fisiológica de sementes e na produtividade de sementes de soja, havendo a necessidade de se realizarem mais pesquisas visando melhor esclarecer o correto manejo da cultura em função destes fatores nos diferentes sistemas produtivos.

\section{CONCLUSÃO}

As diferentes combinações e dosagens de B e Zn, aplicados via foliar na cultura da soja não melhoraram os teores foliares nutricionais, os componentes da produção e produtividade de sementes da soja, assim como a qualidade fisiológica das sementes.

\section{REFERÊNCIAS BIBLIOGRÁFICAS}

BEVILAQUA, G. A. P.; SILVA FILHO, P. M.; POSSENTI, J. C. Aplicação foliar de cálcio e boro e componentes de rendimento e qualidade de sementes de soja. Ciência Rural, Santa Maria, v. 32, n. 1, p.31-34, 2002. Disponível em: <http://www.scielo.br/ /cr/v32n1/a06v32n1.pdf >. Acesso em: 15 set. 2017. 
BLAKESLEY, D.; WESTON, G. D.; HALL, J. F. The role of endogenous auxin in root initiation. Plant Growth Regulation, Netherlands, v. 10, p.341-353, 1991.

BOARETTO, A. E.; TIRITAN, C. S.; MURAOKA, T. Effects of foliar applications of boron on citrus fruit and on foliage and soil boron concentration. In: BELL, R. W.; RERKASEM, B. (Eds.). Boron in soils and plants. London: Kluwer Academic Publishers, 1997. p. 121-123.

BRASIL. Ministério da Agricultura, Pecuária e Abastecimento. Instrução Normativa 25/2005, 16 de dezembro de 2005. Anexo IX - Padrões para produção e comercialização de sementes de soja. Diário Oficial da União, Brasília - DF, Seção 1, p.18, 2005.

BRASIL. Ministério da Agricultura, Pecuária e Abastecimento. Regras para análise de sementes. Brasília, DF: Mapa/ACS, 2009. 399 p.

BROCH, D. L.; FERNANDES, C. H. Resposta da soja à aplicação de micronutrientes. Maracaju, MS: Fundação MS, 1999. 56 p. (Informativo Técnico 02/99).

CARVALHO, N. M.; NAKAGAWA, J. Sementes: ciência, tecnologia e produção. Funep: Jaboticabal, 2000. 588 p.

CERETTA, C. A.; PAVINATO, A.; PAVINATO, P. S.; MOREIRA, I. C. L.; GIROTTO, E.; TRENTIN, E. F. Micronutrientes na soja: produtividade e análise econômica. Ciência Rural, Santa Maria, v. 35, n. 3, p.576-581, 2005. Disponível em: <http://www.scielo.br /cr/v35n3/a13v35n3.pdf >. Acesso em: 19 set. 2017.

COMPANHIA NACIONAL DE ABASTECIMENTO - CONAB. Acompanhamento da safra brasileira de grãos, Quarto Levantamento - Safra 2014/15, v. 2, n. 4, p.1-90 2015. Disponível em: <http://www.conab.gov.br>. Acesso em: 14 jun. 2015.

COSTA, N. P.; MESQUiTA, C. M.; MAURINA, A. C.; FRANÇA NETO, J. B.; KRZYZANOWSKI, F. C.; HENNING, A. A. Qualidade fisiológica, física e sanitária de sementes de soja produzidas no Brasil. Revista Brasileira de Sementes, Londrina, v. 25, n. 1, p.128-132, 2003. Disponível em: 〈http://www.scielo.br/rbs/v25n1/19641.pdf>. Acesso em: 19 set. 2017.

COSTA, N. R.; ANDREOTTI, M.; UliAn, N. A.; PARIZ, C. M.; CAVASANO, F. A.; SANTOS, F. G. Estimativa do custo de produção da soja em sucessão a espécies forrageiras em diferentes épocas de semeadura. Revista Tecnologia \& Ciência Agropecuária, João Pessoa, v. 7, n. 5, p.19-23, 2013.

COSTA, N. R.; ANDREOTTI, M.; ULIAN, N. A.; COSTA, B. S.; PARIZ, C. M.; CAVASANO, F. A.; TEIXEIRA FILHO, M. C. M. Produtividade da soja sobre palhada de forrageiras semeadas em diferentes épocas e alterações químicas no solo. Revista Brasileira de Ciências Agrárias, Recife, v. 10, n. 1, p.8-16, 2015.

DIAS, M. A. N.; PINTO, T. L. F.; MONDO, V. H. V.; CICERO, S. M.; PEDRINI, L. G. Direct effects of soybean seed vigor on weed competition. Revista Brasileira de Sementes, 
Londrina, v. 33, n. 2, p.346-351, 2011. Disponível em: <http://www.scielo.br/rbs/v33n2/17.pdf>. Acesso em: 10 abr. 2018.

EMPRESA BRASILEIRA DE PESQUISA AGROPECUÁRIA - EMBRAPA. Tecnologias de produção de soja - Região Central do Brasil, 2007. Londrina: Embrapa Soja, 2006. 239 p. (Sistemas de produção, 11).

FERREIRA, D. F. Sisvar: a computer statistical analysis system. Ciência e Agrotecnologia, Lavras, v. 35, n. 6, p.1039-1042, 2011.

FERNANDES, A. R.; PAIVA, H. N.; CARVALHO, J. G.; MIRANDA, R. P. Crescimento e absorção de nutrientes por mudas de freijó (Cordia goeldiana Huber) em função de doses de fósforo e de zinco. Revista Árvore, Viçosa, v. 31, n. 4, p.599-608, 2007.

GONÇALVES JÚNIOR, A. C.; NACKE, H.; MARENGONI, N. G.; CARVALHO, E. A.; COELHO, G. F. Produtividade e componentes de produção da soja adubada com diferentes doses de fósforo, potássio e zinco. Ciência e Agrotecnologia, Lavras, v. 34, n. 3, p.660666, 2010.

HARTER, F. S.; BARROS, A. C. S. A. Cálcio e silício na produção e qualidade de sementes de soja. Revista Brasileira de Sementes, Londrina, v. 33, n. 1, p.54-60, 2011. Disponível em: <http://www.scielo.br/rbs/v33n1/06.pdf>. Acesso em: 18 abr. 2018.

KAPPES, C.; GOLO, A. L.; CARVALHO, M. A. C. Doses e épocas de aplicação foliar de boro nas características agronômicas e na qualidade de sementes de soja. Scientia Agraria, v. 9, n. 3, p.291-297, 2008.

KRZYZANOWSKI, F. C.; GILIOLI, J. L.; MIRANDA, L. C. Produção de sementes nos cerrados. In: ARANTES, N. E.; SOUZA, P. I. M. (Ed.). Cultura da soja nos cerrados. Piracicaba: Potáfos, 1993. p. 465-522.

LANA, R. M. Q.; BUCK, G. B.; LANA, A. M. Q.; PEREIRA, R. P. Doses de multifosfato magnesiano aplicados a lanço em pré-semeadura, sob sistema plantio direto: cultura da soja. Ciência e Agrotecnologia, Lavras, v. 31, n. 6, p.1654-1660, 2007. Disponível em: <http://www.scielo.br/pdf/cagro/v31n6/a08v31n6.pdf>. Acesso em: 25 abr. 2018.

MALAVOLTA, E.; VITTI, G. C.; OLIVEIRA, S. A. Avaliação do estado nutricional das plantas: princípios e aplicações. 2. ed. Piracicaba: Associação Brasileira para Pesquisa da Potassa e do Fosfato, 1997. 319 p.

MALAVOLTA, E. Manual de nutrição mineral de plantas. São Paulo: Agronômica Ceres, 2006. $638 \mathrm{p}$.

MARCANDALLI, L. H.; LAZARINI, E.; MALASPINA, I. C. Épocas de aplicação de dessecantes na cultura da soja: qualidade fisiológica de sementes. Revista Brasileira de Sementes, Londrina, v. 33, n. 2, p.241-250, 2011.

MARCOS FILHO, J. Fisiologia de sementes de plantas cultivadas. Piracicaba: Fealq, $2005.495 \mathrm{p}$. 
MENDES, I. C.; REIS JUNIOR, F. B.; HUNGRIA, M.; SOUSA, D. M. G.; CAMPO, R. J. Adubação nitrogenada suplementar tardia em soja cultivada em latossolos do Cerrado. Pesquisa Agropecuária Brasileira, Brasília, v. 43, n. 8, p.1053-1060, 2008. Disponível em: 〈http://www.scielo.br/pab/v43n8/v43n8a15.pdf>. Acesso em: 18 abr. 2018.

MENGEL, K.; KIRKBY, E. A. Principles of plant nutrition. Worblaufer-Bern: International Potash Institute, 1979. 579 p.

NAKAGAWA, J. Testes de vigor baseados no desempenho das plântulas. In: KRZYZANOWSKI, F. C.; VIEIRA, R. D.; FRANÇA-NETO, J. B. Vigor de sementes: conceitos e testes. Londrina: ABRATES, 1999. cap. 2, p. 9-13.

RAIJ, B. van; CANTARElla, H.; QUAGGiO, J. A.; FURlani, A. M. C. Recomendações de Adubação e Calagem para o Estado de São Paulo. 2.ed. Campinas: Instituto Agronômico, 1997. 285 p. (Boletim Técnico, 100).

RAIJ, B. van; ANDRADE, J. C.; CANTARELLA, H.; QUAGGIO, J. A. Análise química para avaliação da fertilidade de solos tropicais. Campinas: Instituto Agronômico, 2001. $284 \mathrm{p}$.

SÁ, M. E.; LAZARINI, E. Relação entre os valores de condutividade elétrica e níveis de emergência em sementes de diferentes genótipos de soja. Informativo Abrates, Londrina, v. 5, n. 2, p.143, 1995.

SANTOS, H. G.; JACOMINE, P. K. T.; ANJOS, L. H. C.; OLIVEIRA, V. A.; OLIVEIRA, J. B.; COELHO, M. R.; LUMBRERAS, J. F.; CUNHA, T. J. F. (Ed.). Sistema brasileiro de classificação de solos. 2. ed. Rio de Janeiro: Embrapa Solos, 2006. 306 p.

SOUZA, L. C. D.; SÁ, M. E.; CARVALHO, M. A. C.; SIMIDU, H. M. Produtividade de quatro cultivares de soja em função da aplicação de fertilizante mineral foliar a base de cálcio e boro. Revista de Biologia e Ciências da Terra, Londrina, v. 8, n. 2, p.37-44, 2008.

TAIZ, L.; ZEIGER. Fisiologia vegetal. 4.ed. Porto Alegre: Artmed, 2009. 819 p.

TOLEDO, M. Z.; CAVARIANI, C.; FRANÇA-NETO, J. B. Qualidade fisiológica de sementes de soja colhidas em duas épocas após dessecação com glyphosate. Revista Brasileira de Sementes, Londrina, v. 34, n. 1, p.134-142, 2012. Disponível em: <http://www.scielo.br/pdf/rbs/v34n1/a17v34n1.pdf>. Acesso em: 13 mai. 2018.

VAZQUEZ, G. H.; CARVALHO, N. M.; BORBA, M. M. Z. Redução na população de plantas sobre a produtividade e a qualidade fisiológica da semente de soja. Revista Brasileira de Sementes, Londrina, v. 30, n. 2, p.01-11, 2008. Disponível em: <http://www.scielo.br/pdf/rbs/v30n2/a01v30n2.pdf>. Acesso em: 13 mai. 2018.

VIEIRA, R. D. Teste de condutividade elétrica. In: VIEIRA, R. D.; CARVALHO, N. M. (Ed.). Testes de vigor em sementes. Jaboticabal: FUNEP, 1994. p. 103-132. 